Revue bibliographique pour le domaine irano-aryen

\title{
Éloïse Brac de la Perrière. « Manuscripts in Bihari Calligraphy: Preliminary Remarks on a Little- Known Corpus »
}

\section{Frantz Chaigne}

\author{
(2) OpenEdition \\ Journals \\ Édition électronique \\ URL : http://journals.openedition.org/abstractairanica/42588 \\ DOI : 10.4000/abstractairanica.42588 \\ ISBN : 1961-960X \\ ISSN : 1961-960X \\ Éditeur : \\ CNRS (UMR 7528 Mondes iraniens et indiens), Éditions de l'IFRI
}

\section{Référence électronique}

Frantz Chaigne, «Éloïse Brac de la Perrière. « Manuscripts in Bihari Calligraphy: Preliminary Remarks on a Little-Known Corpus » », Abstracta Iranica [En ligne], Volume 37-38-39 | 2018, document 1, mis en ligne le 10 mars 2018, consulté le 02 octobre 2020. URL : http://journals.openedition.org/ abstractairanica/42588 ; DOI : https://doi.org/10.4000/abstractairanica.42588

Ce document a été généré automatiquement le 2 octobre 2020.

Tous droits réservés 


\title{
Éloïse Brac de la Perrière. « Manuscripts in Bihari Calligraphy: Preliminary Remarks on a Little- Known Corpus »
}

\author{
Frantz Chaigne
}

\section{RÉFÉRENCE}

Éloïse Brac de la Perrière. « Manuscripts in Bihari Calligraphy: Preliminary Remarks on a Little-Known Corpus », Muqarnas 33 (2016), p. 63-90.

1 L'A. signe ici un article qui s'inscrit dans la continuité de ses travaux sur les manuscrits indiens pré-modernes. En 2008, elle publiait en effet L'art du livre dans l'Inde des sultanats (PUPS), avant de codiriger avec Monique Buresi le volume collectif Le coran de Gwalior : Polysémie d'un manuscrit à peintures paru en 2016 (De Boccard).

2 Le présent travail s'appuie sur l'examen d'un conséquent corpus de 137 items (manuscrits et feuillets isolés) dont deux seulement ne sont pas coraniques. Comme signalé par l'A., une des difficultés de cette étude réside dans le conservatisme, a priori source d'uniformité, qui se manifeste dans cette production. Dans un premier temps, elle décrypte avec précision ce type de graphie et son évolution, tout en se livrant à une analyse historiographique. Cette approche contribue à élucider les origines de cette écriture. Suit une présentation du corpus, découpé en un groupe "pionnier», un deuxième groupe homogène "classique " de corans de belle facture, et un dernier groupe de corans "communs", chacun de ces ensembles étant caractérisé. Vient ensuite une description des mises en page, enluminures et attributs fonctionnels, à l'instar des indications de lecture ou de la présence de fālnāma.

3 En procédant à des rapprochements précis avec les décors et usages de tuniques apotropaïques et de textiles jains, L'A. suggère de manière convaincante des usages 
ésotériques pour ces manuscrits, vraisemblablement copiés pour d'érudites confréries soufies. L'A. démontre ensuite qu'il est possible d'esquisser une chronologie pour ce corpus en se basant sur l'étude des enluminures et des graphies, mais signale les limites de cette méthode dans l'identification des lieux de production. Enfin, elle se penche sur un groupe restreint de corans indiens somptueux se singularisant par une graphie en muhaqaqq et qui seraient cette fois-ci attribuables à un milieu de production princier. Cet article soulève donc nombre de questions relatives à la sociologie de la production. Par l'acuité de la taxonomie engendrée par ces études de cas approfondies, il fournit de nombreux outils qui permettent d'appréhender les pistes des recherches à venir en vue d'élucider les ressorts les plus intimes et les plus divers de cette production.

\section{AUTEURS}

\section{FRANTZ CHAIGNE}

Chercheur associé, CNRS, Orient \& Méditerranée-«Islam médiéval» 